\title{
Ploidy Levels and Genome Sizes of Berberis L. and Mahonia Nutt. Species, Hybrids, and Cultivars
}

\author{
Todd J. Rounsaville ${ }^{1}$ and Thomas G. Ranney ${ }^{2,3}$ \\ Department of Horticultural Science, Mountain Horticultural Crops \\ Research and Extension Center, North Carolina State University, 455 \\ Research Drive, Mills River, NC 28759
}

Additional index words. chromosome number, cytology, DNA content, flow cytometry, genome size, polyploidy, systematics, taxonomy

\begin{abstract}
An extensive survey of genome sizes and ploidy levels was conducted for a diverse collection of Berberis and Mahonia taxa (Berberidaceae). Propidium iodide flow cytometric analysis was conducted using Pisum sativum $\mathrm{L}$. 'Ctirad' $(2 \mathrm{C}$ DNA $=8.76 \mathrm{pg})$ as an internal standard to determine genome sizes. Mean $\mathbf{1 C}_{X}$ genome sizes varied between the two Mahonia subgenera (Occidentales $=1.17 \pm 0.02$, Orientales $=1.27 \pm 0.01$ ), whereas those of Berberis subgenera were similar (Australes $=1.45 \pm 0.03$, Septentrionales $=1.47 \pm$ 0.02) and each significantly larger than those of Mahonia. Traditional cytology was performed on representative species to calibrate genome sizes with ploidy levels. Polyploidy among both wild and cultivated taxa was found to be rare. Although the majority of species were determined to be diploid with $2 n=2 x=28$, artificially induced autopolyploid Berberis thunbergii seedlings were confirmed to be tetraploid and an accession of Mahonia nervosa was confirmed to be hexaploid. Genome size and ploidy level reports for the majority of taxa sampled are presented for the first time and are intended to be of use to plant breeders, ecologists, and systematists.
\end{abstract}

The sister genera Berberis L. and Mahonia Nutt. represent the two largest groups within the family Berberidaceae, consisting of $\approx 400$ and 100 species, respectively (Ahrendt, 1961; Kim et al., 2004). This highly ornamental group of shrubs and small trees is valued for their evergreen or multicolored leaves, brilliant flowers, and often showy fruit. The two genera have also been recognized for their pharmaceutical and medicinal properties (Alvarez et al., 2009) as well as their use in the printing and dyeing industry (Yan-Jun et al., 2006). Distribution of the two genera is nearly worldwide with centers of diversity in southern Asia as well as Central and South America and with minor representation in North America, Europe, Africa, and the Pacific Islands (Ahrendt, 1961).

Taxonomic standing of Mahonia and Berberis as distinct genera has been the subject of much debate among botanists and horticulturists. Before the development of DNA-based phylogenetics, morphological characters such as leaf and stem complexity, inflorescence

Received for publication 22 Apr. 2010. Accepted for publication 28 May 2010.

We thank Tom Eaker, Nathan Lynch, Joel Mowrey, and the staff of the Mountain Horticultural Crops Research Station for their excellent technical assistance. We also thank Tony Avent, Ozzie Johnson, Todd Wiegardt, and the staff of the JC Raulston Arboretum and Bartlett Arboretum for their generous donations of sample material.

${ }^{1}$ Graduate Research Assistant.

${ }^{2}$ Professor.

${ }^{3}$ To whom reprint requests should be addressed; e-mail tjrounsa@ncsu.edu. structure, and floral anatomy had served to distinctly separate Mahonia from Berberis. However, Mahonia section Horridae Fedde (approximately nine species), which includes M. freemontii (Torr.) Fedde, M. haematocarpa (Wooton) Fedde, M. nevinii (A. Gray) Fedde, and M. trifoliolata (Moric.) Fedde, exhibits a blend of taxonomic features intermediate between Mahonia and Berberis (Ahrendt, 1961; Whittemore, 1997). These morphological inconsistencies have led some (Laferriere, 1997; Marroquin, 1993; Whittemore, 1997) to adopt a unified treatment of all Berberis and Mahonia species within Berberis. Nevertheless, the obvious difference in physical appearance between the two genera, with compound leaves within Mahonia versus simple leaves within Berberis, makes a unified circumscription hard to reconcile, and consequently, the horticultural field generally maintains the two groups as separate genera (Ahrendt, 1961; Dirr, 2009; Hinkley, 2009; Huxley et al., 1992; Yan-Jun et al., 2006).

When the taxonomy is viewed sensu Ahrendt, Berberis and Mahonia are each broken down into two subgenera set forth by Ahrendt (1961) and Schneider (1905). Within Berberis, the Australes C.K. Schneid. includes all the species from Central and South America; the remaining species are placed in the Septentrionales C.K. Schneid. and occur entirely in the northern hemisphere save for two in East Africa and one in Java and Sumatra (Ahrendt, 1961). Conversely, Mahonia are grouped longitudinally with those of the Eastern hemisphere in subgenus Orientales Ahrendt and all those of the Western hemisphere [with the notable excep- tion of M. nervosa (Pursh) Nutt.] in subgenus Occidentales Ahrendt.

Recent phylogenetic analysis based on internal transcribed spacer (ITS) sequencing (Kim et al., 2004) has yielded further insight into the taxonomic relationships and evolutionary history of Mahonia and Berberis. For example, the postulation of Ahrendt (1961) of Mahonia as the progenitor of Berberis was supported. Examining the contemporary dispersal of the two genera from South America northward reveals that although the distinctive compound-leaved Mahonia is first encountered in Central America, a number of Berberis characters persist within Mahonia much further north. These transitional species, representing the aforementioned Mahonia section Horridae, showed a closer relationship with Berberis and thus a paraphyletic subgenus Occidentales (Kim et al., 2004). Although ITS phylogeny supported the subgenera proposed by Ahrendt (1961) and Schneider (1905), groupings below the subgeneric levels were not supported (Kim et al., 2004). Furthermore, $M$. nervosa was retained within the Orientales, albeit with weak support.

Along with the monotypic herb Ranzania japonica T. Ito, Berberis and Mahonia form a monophyletic clade within Berberidaceae in which base chromosome number is $x=7$ (Kim and Jansen, 1998). As Dermen (1931) noted in his cytological studies, chromosomes among widespread species of both genera are of similar size. Furthermore, artificial intergeneric hybridization events between Mahonia and Berberis originated in Europe as early as 1854 (Dirr, 2009). Despite a number of successful intergeneric hybrids ( $\times$ Mahoberberis C.K. Schneid.), the resulting progeny have been horticultural curiosities at best, typically regarded as inferior to both parent taxa (Phillips and Barber, 1981). $\times$ Mahoberberis tend to exhibit numerous leafmorphs among single plants, and in general flowering and fruiting of the hybrids is known to be rare or nonexistent (Dirr, 2009; Wyman, 1958). In addition, all $\times$ Mahoberberis hybrids have been comprised of only one species of Mahonia [M. aquifolium (Pursh) Nutt.], and the cross appears uni-directional with Mahonia only functioning as the maternal parent (Dirr, 2009; personal observation), further suggesting that the two genera are largely incompatible. Conversely, hybrids among species of Berberis and among species of Mahonia are commonplace (Huxley et al., 1992; personal observation).

Polyploidization is a significant phenomenon in the plant kingdom that can play a role in rapid genomic rearrangement, development of novel traits and adaptations, reproductive isolation, and can ultimately lead to speciation (Adams and Wendel, 2005; Soltis and Burleigh, 2009). Furthermore, polyploidy is an important consideration in plant breeding because it can influence crossability, morphology, fertility, and gene expression (Chen and Ni, 2006; Soltis et al., 2004). Sampling of ploidy levels has been very limited for Mahonia taxa. Mahonia aquifolium, M. napaulensis DC., M. repens (Lindl.) 
G. Don., and $M$. japonica (Thunb.) DC. have been reported to be diploid with $2 n=2 x=28$ (Dermen, 1931; Xu et al., 1992). In other cases, M. aquifolium and $M$. nervosa were reported to be tetraploid with $2 n=4 x=56$ (Taylor and Taylor, 1997). Reports on 45 Berberis species found diploids, $2 n=2 x=28$, including $B$. koreana Palib., $B$. seiboldii Miq., B. thunbergii DC., B. vulgaris L., and $B$. yunnanensis Franch. as well as tetraploids, $2 n=4 x=56$, including $B$. buxifolia Lam., $B$. heterophylla Juss. ex Poir., and B. turcomanica Kar. (Bottini et al., 2000; Dermen, 1931).

Independent of variations in ploidy level, information on base genome size (base DNA content) can be used as an indicator of genome evolution and taxonomic relationships (Greilhuber, 1998; Vinogradov, 1994; Zonneveld and Duncan, 2010; Zonneveld and Van Iren, 2001), lending insight into species evolution and potential breeding applications. As it relates to breeding, disparities in genome sizes can reflect differences in chromosome sizes and arrangement that may influence crossability and fertility of hybrid progeny (Zonneveld, 2009). There are no published reports of Mahonia genome size, and those of Berberis are extremely limited in both number of taxa and species diversity. Previous reports of genome size among Berberis were determined using Feulgen microspectrophotometry with diploid species constituting a range of $1.5 \mathrm{pg}$ for $B$. bidentata Lechler to $3.6 \mathrm{pg}$ for B. empetrifolia Lam. (Bottini et al., 2000). A desirable alternative to microspectrophotometry is flow cytometry, which allows for much greater ease in sample preparation, rapid determination of genome size, and can be accurately performed using a variety of plant tissues (Doležel and Bartos, 2005; Doležel et al., 1998). For closely related taxa, in which genome sizes are relatively conserved, flow cytometry can also be used for determination of ploidy level. Although a number of different fluorochromes may be used to stain DNA, many including 4', 6-diamidino-2-phenylindole, Hoechst 33258, and olivomycin are exclusive to either AT or CG bps, whereas propidium iodide (PI) is known to be largely non-specific with only a slight preference toward CG (Doležel et al., 1998; Vinogradov, 1994).

Considering the tremendous diversity and crossability found in Berberis and Mahonia, the potential for breeding improved hybrids is considerable. However, a greater understanding of genome sizes and ploidy levels within these genera would greatly enhance future breeding efforts. Although basic information on chromosome numbers, genome sizes, and ploidy levels have been reported for some Berberis and Mahonia, sampling has been limited and little is known about ploidy levels of specific clones or cultivars. The objectives of this research were to conduct an extensive survey of genome sizes and ploidy levels of species, hybrids, and cultivars of Berberis and Mahonia using a combination of flow cytometry and traditional cytology. Taxa included for this survey exhibit attributes of value for the ornamental plant breeder and are representative of each major phylogenetic clade. As a result of the unresolved nature of the generic classification, and for purposes of comparison, we accept the treatment of Ahrendt (1961), whom conducted the last thorough review of the genera.

\section{Materials and Methods}

A diverse collection of Berberis and Mahonia taxa were obtained from various institutions, gardens, and private collectors. All sampled plants from the Mountain Horticulture Crops Research Station (MHCRS) were container-grown, whereas additional sample material shared with the authors was collected from field-grown plants (Table 1). Sampled taxa represented species from each of the four subgenera (Australes, Septentrionales, Occidentales, and Orientales), many common cultivars, including interspecific hybrids, and a few purported artificially induced autopolyploids.

Flow cytometry was conducted on tissue $\left(0.5 \mathrm{~cm}^{2}\right)$ taken from recently expanded leaves using a hole punch. Leaf tissue for each sample as well as an internal standard (Pisum sativum 'Ctirad' 2C DNA $=8.76 \mathrm{pg}$ ) was finely diced with a razor blade in a petri dish containing $500 \mu \mathrm{L}$ of nuclei extraction buffer. On being filtered into a small test tube using a $50-\mu \mathrm{m}$ filter, a solution containing 2 $\mathrm{mL}$ staining buffer, $6 \mu \mathrm{L}$ RNase A, and $12 \mu \mathrm{L}$ PI (CyStain PI absolute P; Partec, Münster, Germany) was added, and the samples were moved to a refrigerator at $4{ }^{\circ} \mathrm{C}$ for $1 \mathrm{~h}$. A flow cytometer (Partec PA-II; Partec) was used to analyze the stained nuclei with a minimum of 5000 counts per sample and two subsamples conducted for each taxon. Flow cytometry was conducted during the spring and summer of 2009 when fresh leaf material was available for sample. Holoploid, 2C genome size was calculated as: $2 \mathrm{C}=$ genome size of standard $\times$ (mean fluorescence value of sample/mean fluorescence value of standard). Genome size values presented within Table 1 represent the mean value of two subsamples conducted for each taxon. The relationship between ploidy levels and genome sizes was determined for plants with documented chromosome numbers (Bottini et al., 2000; Xu et al., 1992). Mean $1 C_{X}$ monoploid genome size (i.e., DNA content of the non-replicated base set of chromosomes with $\mathrm{x}=14$ ) was calculated as (2C genome size/ploidy level) to assess variability in base genome size. Data were subjected to analysis of variance and means separation using the Waller procedure to compare means of genera and subgenera (SAS Institute Inc., Cary, NC).

Traditional cytology was conducted to verify previous work and calibrate genome size with ploidy level. Between 0800 and $0900 \mathrm{HR}$, actively growing root tips $\approx 5 \mathrm{~mm}$ in length were removed from container-grown plants and placed into small vials of $2 \mathrm{~mm} 8$ hydroxyquinoline. The vials were left in the dark for $2 \mathrm{~h}$ at room temperature followed by $2 \mathrm{~h}$ in darkness at $4{ }^{\circ} \mathrm{C}$. Roots tips were then thoroughly rinsed in cold distilled $\mathrm{H}_{2} \mathrm{O}$, blotted dry, and transferred to a fixative of
(3:1) 95\% ethanol:propionic acid overnight at room temperature. After 16 to $24 \mathrm{~h}$ in fixative, the root tissue was rinsed with $70 \%$ ethanol and transferred to storage in $70 \%$ ethanol at $4{ }^{\circ} \mathrm{C}$. When time permitted, root tissue was removed from cold storage and hydrolyzed in a solution of (3:1) $95 \%$ ethanol: $12 \mathrm{~N} \mathrm{HCl}$ for 5 to $10 \mathrm{~s}$. Root tips were then placed into a drop of modified carbol fuschin stain (Kao, 1975) on a glass microscope slide and gently squashed with a coverslip. Chromosomes were counted using oil immersion at $1500 \times$.

\section{Results and Discussion}

Cytology performed on Mahonia eurybracteata Fedde 'Soft Caress' (MHCRS 2008-267) and B. thunbergii var. atropurpurea 'Concorde' confirmed them to both be diploid, providing an additional confirmation and calibration of ploidy level with genome size. Flow cytometry was subsequently found to be an effective method for determining genome sizes and ploidy levels of Mahonia and Berberis (Table 1). The base, $1 \mathrm{C}_{\mathrm{X}}$, genome size for Mahonia varied for each subgenus with a mean of $1.17 \mathrm{pg}$ for $\mathrm{Occi}$ dentales and $1.27 \mathrm{pg}$ for Orientales (Table 2). There was no difference in $1 \mathrm{C}_{\mathrm{X}}$ genome size between the two subgenera of Berberis, but plants in the genus Berberis had a significantly higher mean (1.45 pg) than either subgenus of Mahonia. These data indicate that a significantly greater $(\approx 18 \%)$ expansion in genome size occurred during the evolution of Berberis compared with Mahonia. The substantial difference in genome size between Mahonia and Berberis could compromise fertility of intergeneric hybrids as a result of chromosomal sterility and may explain why these hybrids are typically sterile. Of additional interest are the genome sizes for species in Mahonia section Horridae (Occidentales). Although ITS phylogeny (Kim et al., 2004) indicated plants in this section were more closely allied with Berberis than to Mahonia, the mean $1 \mathrm{C}_{\mathrm{X}}$ value for $M$. haematocarpa, M. nevinii, and $M$. trifoliolata (all in section Horridae) was 1.19 pg, significantly lower $(P<0.05)$ than either subgenus of Berberis or Mahonia subgenus Orientales but consistent with Mahonia subgenus Occidentales.

Within Berberis subgenus Septentrionales, diploid 2C genome sizes ranged from $2.48 \mathrm{pg}$ for B. wilsonii var. stapfiana (C.K. Schneid.) C.K. Schneid. (JCRA, accession \#E41) to $3.36 \mathrm{pg}$ for B. sieboldii (MHCRS 2005-179) with a mean of $2.94 \mathrm{pg}$ for the subgenus. Only four taxa were available for sampling from Berberis subgenus Australes and ranged in $2 \mathrm{C}$ genome size from $2.77 \mathrm{pg}$ for B. Xstenophylla Hort. (MHCRS 2000$210)$ to $3.02 \mathrm{pg}$ for Berberis trigona Kunze ex Poepp. \& Endl. 'Orange King' (MHCRS 2003-053) with a mean of $2.90 \mathrm{pg}$ for the subgenus, well within the range found for Berberis subgenus Septentrionales. No natural polyploids were identified among the Berberis sampled in this study. However, 
Table 1. Mean 2C genome sizes and ploidy levels of Berberis and Mahonia species, hybrids, and cultivars.

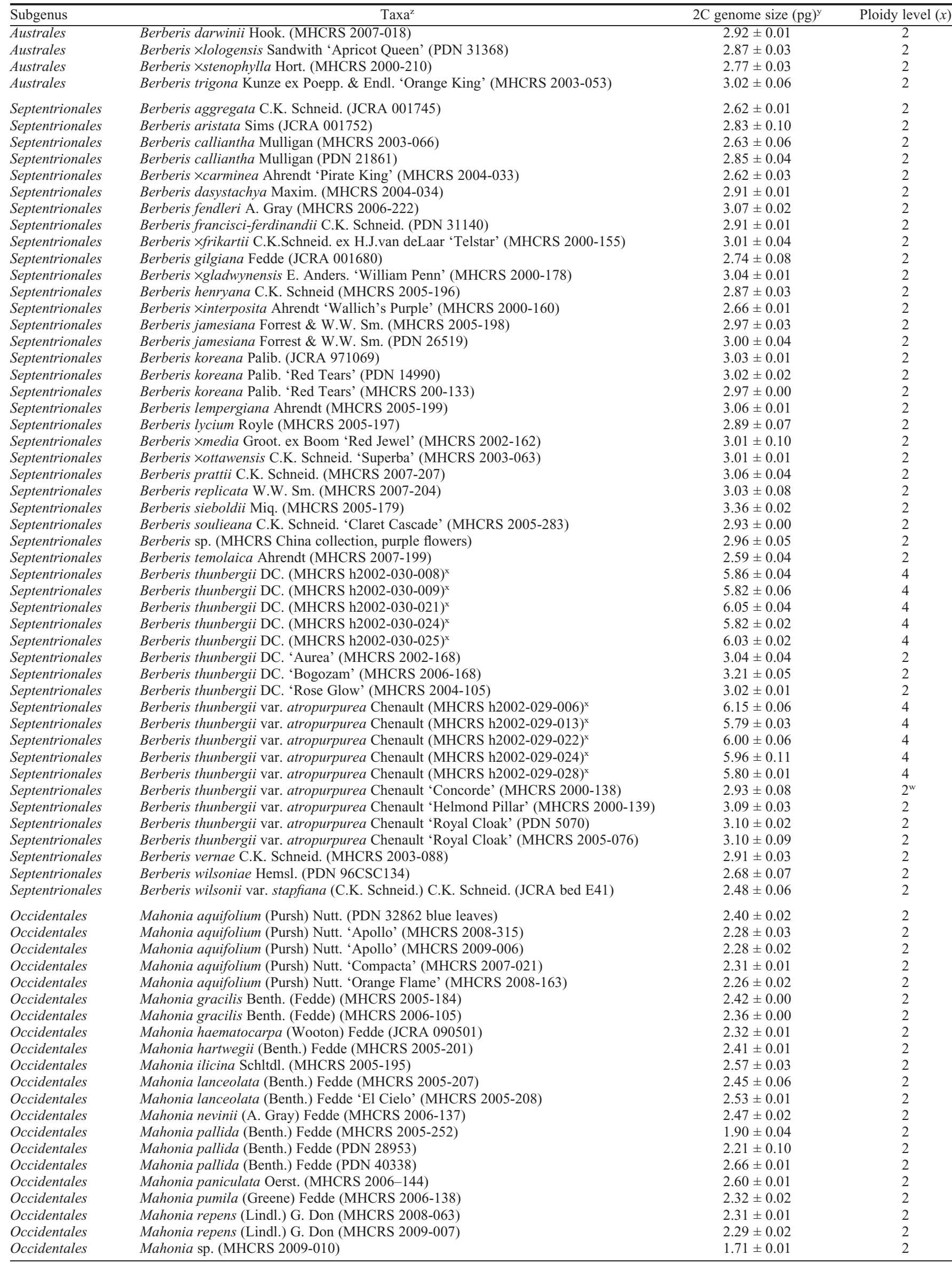


Table 1. (Continued)



${ }^{\mathrm{z}}$ Taxa (source and accession). BA = Bartlett Arboretum, Charlotte, NC; JCRA = JC Raulston Arboretum, Raleigh, NC; MHCRS = Mountain Horticultural Crops Research Station, Mills River, NC; OJ = Mr. Ozzie Johnson, Atlanta, GA; PDN = Plant Delights Nursery, Juniper Level Botanical Garden, Raleigh, NC.

${ }^{\mathrm{y}}$ Values are means \pm SEM.

${ }^{x}$ Taxa represent open-pollinated seedlings of $B$. thunbergii that were treated with oryzalin to induce polyploidy.

${ }^{\mathrm{w}}$ Chromosome number and ploidy level was confirmed by cytology.

Table 2. Mean $1 \mathrm{C}_{\mathrm{X}}$ genome size among the four subgenera of Berberis and Mahonia

\begin{tabular}{llcc}
\hline Genus & Subgenus & $1 \mathrm{C}_{\mathrm{X}}$ genome size $(\mathrm{pg})$ & Taxa sampled (no.) \\
\hline Berberis & Australes & $1.45 \pm 0.03 \mathrm{C}^{\mathrm{z}}$ & 4 \\
& Septentrionales & $1.47 \pm 0.02 \mathrm{C}$ & 48 \\
Mahonia & Occidentales & $1.17 \pm 0.02 \mathrm{~A}$ & 24 \\
& Orientales & $1.27 \pm 0.01 \mathrm{~B}$ & 48 \\
\hline
\end{tabular}

${ }^{\mathrm{z}}$ Values are means \pm SEM. Values followed by different letters, within a column, are significantly different $(P \leq 0.05)$.

artificially induced autopolyploid seedlings from both Berberis thunbergii var. atropurpurea and Berberis thunbergii 'Rose Glow' yielded mean $2 \mathrm{C}$ genome sizes of $5.93 \mathrm{pg}$, effectively confirming them as tetraploids.
Although the previous report on Berberis genome sizes by Bottini et al. (2000) was exclusive to the Australes, this subgenus was only modestly sampled in our study, and therefore there was very little overlap be- tween the studies. Our 2C genome size of $2.92 \mathrm{pg}$ for $B$. darwinii Hook. was congruent with the range of 2.88 to $3.22 \mathrm{pg}$ reported by Bottini et al. (2000) in wild populations of the species. Additionally, Berberis trigona (syn. Berberis linearifolia Phil.) cultivar Orange King had a genome size slightly less (3.02 pg) than the reported range of 3.24 to $3.57 \mathrm{pg}$ (Bottini et al., 2000).

Genome sizes of diploid Mahonia subgenus Occidentales ranged from $1.71 \mathrm{pg}(M$. sp., Mexican origin; MHCRS 2009-010) to 2.66 pg [M. pallida (Benth.) Fedde PDN 40338] with a mean of $2.35 \mathrm{pg}$. Subgenus Orientales had a higher mean of $2.55 \mathrm{pg}$ for diploids, ranging from $2.28 \mathrm{pg}(M$. sp.; OJ 
04052) to $2.76 \mathrm{pg}$ (M. sp.; PDN CPC 6.5.01.1). We have not found other published reports of 2C genome sizes for Mahonia. No tetraploid Mahonia were identified among the taxa sampled for this project. However, prior reports (Taylor and Taylor, 1997) have documented tetraploid clones of $M$. aquifolium and $M$. nervosa, indicating that these species may include a polyploid series. The only polyploid Mahonia found in this survey was M. nervosa (MHCRS 2008-062), which was estimated to be hexaploid $(2 n=6 x=84)$ with a genome size of $7.45 \mathrm{pg}$. Interestingly, $M$. nervosa is the only new world species placed within subgenus Orientales based on both morphology (Ahrendt, 1961) and DNA phylogeny (Kim et al., 2004).

Overall, this study demonstrates that PI flow cytometry is an extremely useful tool for studying genome sizes and polyploidy in both Berberis and Mahonia. Substantial differences in base $1 C_{X}$ genome size between Berberis and Mahonia demonstrate considerable variation in genome evolution between these groups. However, genome sizes were strongly conserved within Berberis and $M a$ honia subgenera, which allowed for rapid and consistent calibration with ploidy levels. Although polyploidy appears to be uncommon among species of both Berberis and Mahonia, one accession of $M$. nervosa was found to be hexaploid. Furthermore, artificially induced plants of $B$. thunbergii were confirmed to be tetraploids. Data from this study provide insight into evolutionary history, taxonomic treatment, and information on ploidy levels of specific taxa that will aid in the breeding and development of new hybrids and serve as a valuable database for plant breeders, systematists, and evolutionary biologists.

\section{Literature Cited}

Adams, K.L. and J.F. Wendel. 2005. Novel patterns of gene expression in polyploidy plants. Trends Genet. 21:539-543.
Ahrendt, L.W.A. 1961. Berberis and Mahonia, a taxonomic revision. J. Linnean Soc. London. 57:1-410.

Alvarez, M.A., N.F. Eraso, S.I. Pitta-Alvarez, and P.L. Marconi. 2009. Two-stage culture for producing berberine by cell suspension and shoot cultures of Berberis buxifolia Lam. Biotechnol. Lett. 31:457-463.

Bottini, M.C.J., E.J. Greizerstein, M.B. Aulicino, and L. Poggio. 2000. Relationships among genome size, environmental conditions and geographical distribution in natural populations of NW Patagonian species of Berberis L. Ann. Bot. (Lond.) 86:565-573.

Chen, Z.J. and Z. Ni. 2006. Mechanisms of genomic rearrangements and gene expression changes in plant polyploids. Bioessays 28:240-252.

Dermen, H. 1931. A study of chromosome number in two genera of Berberidaceae: Mahonia and Berberis. J. Arnold Arbor. 12:281-287.

Dirr, M. 2009. Manual of woody landscape plants: Their identification, ornamental characteristics, culture, propagation and uses. 6th Ed. Stipes, Champaign, IL.

Doležel, J. and J. Bartos. 2005. Plant DNA flow cytometry and estimation of nuclear genome size. Ann. Bot. (Lond.) 95:99-110.

Doležel, J., J. Greilhuber, S. Lucretti, A. Meister, M.A. Lysa'k, L. Nardi, and R. Obermayer. 1998. Plant genome size estimation by flow cytometry: Inter-laboratory comparison. Ann. Bot. (Lond.) 82:17-26.

Greilhuber, J. 1998. Intraspecific variation in genome size: A critical reassessment. Ann. Bot. 82:27-35.

Hinkley, D.J. 2009. The explorer's garden shrubs and vines from the four corners of the world. Timber, Portland, OR.

Huxley, A., M. Griffiths, and M. Levy. 1992. The New Royal Horticultural Society dictionary of gardening. Macmillian Press Ltd, London, UK.

Kao, K.N. 1975. A chromosomal staining method for cultured cells, p. 63-64. In: Gambourg, O.L. and L.R. Wetter (eds.). Plant tissue culture methods. NRC Canada, Saskatoon, Canada.

Kim, Y.-D. and R.K. Jansen. 1998. Chloroplast DNA restriction site variation and phylogeny of the Berberidaceae. Amer. J. Bot. 85:1766-1778.

Kim, Y.-D., S.-H. Kim, and L.R. Landrum. 2004. Taxonomic and phytogeographic implications from ITS phylogeny in Berberis (Berberidaceae). J. Plant Res. 117:175-182.

Laferriere, J.E. 1997. Transfer of specifc and infraspecific taxa from Mahonia to Berberis (Berberidaceae). Bot. Zhurn. 82:95-99.

Marroquin, J.S. 1993. Berberidaceae. Flora de Veracruz. Fasciculo 75:1-16.

Phillips, C.E. and P.N. Barber. 1981. Ornamental shrubs. Van Nostrand Reinhold, New York, NY.

Schneider, C.K. 1905. Die Gattung Berberis (Euberberis) Vorarbeiten fur eine monographie. Bull Herb Boissier. Ser. 2:33-48.

Soltis, D.E. and J.G. Burleigh. 2009. Surviving the K-T mass extinction: New perspectives of polyploidization in angiosperms. Proc. Natl. Acad. Sci. USA 106:5455-5456.

Soltis, D.E., P.S. Soltis, and J.A. Tate. 2004 Advances in the study of polyploidy since plant speciation. New Phytol. 161:173-191.

Taylor, R.L. and S. Taylor. 1997. Chromosome numbers of vascular plants of British Columbia. Syesis 10:125-138

Vinogradov, A.E. 1994. Measurement by flow cytometry of genomic AT/CG ratio and genome size. Cytometry 16:34-40.

Whittemore, A.T. 1997. Berberis, p. 276-286. In: Morin, N.R. (ed.). Flora of North America. Vol. 3. Oxford University Press, New York, NY.

Wyman, D. 1958. Two new Mahoberberis hybrids. Arnoldia 18:9-12.

Xu, B.S., R.F. Weng, and M.Z. Zhang. 1992. Chromosome numbers of Shanghai plants. I. Investigatio et Studium. Naturae 12:48-65.

Yan-Jun, Z., A.-P. Meng, J.-Q. Li, H.-S. Dang, and X.-W. Li. 2006. Observation on meiotic behavior in three Mahonia species, with special reference to the intergeneric relationship of Mahonia and Berberis. Caryologia 59:305-311.

Zonneveld, B.J.M. 2009. The systematic value of nuclear genome size for 'all' species of Tulipa L. (Liliaceae). Plant Syst. Evol. 281:217-245.

Zonneveld, B.J.M. and G.D. Duncan. 2010. Genome sizes of Eucomis L'Hér.(Hyacinthaceae) and a description of the new species Eucomis grimshawii G.D. Duncan \& Zonneveld. Plant Syst. Evol. 284:99-109.

Zonneveld, B.J.M. and F. Van Iren. 2001. Genome size and pollen viability as taxonomic criteria: Application to the genus Hosta. Plant Biol. 3:176-185. 